\title{
Short Term Effect of Virtual Reality on Eye Accommodative Ability
}

\author{
Mohd Syarifuddin Mukhtar ${ }^{1}$, Mohd Zulfaezal Che Azemin ${ }^{1}$, Mohd Hafidz Ithnin ${ }^{1}$ and \\ Mohd Izzuddin Mohd Tamrin ${ }^{2}$ \\ ${ }^{1}$ Kulliyyah of Allied Health Sciences, International Islamic University Malaysia, \\ Bandar Indera Mahkota, 25200 Kuantan, Malaysia. \\ ${ }^{2}$ Kulliyyah of ICT, International Islamic University Malaysia, Gombak, 53100 Kuala Lumpur, \\ Malaysia.
}

\begin{abstract}
Virtual reality (VR) is a fast-growing technology in the world today. Many countries use virtual reality for many purposes such as education, military and entertainment. Despite the benefits of VR, harmful effects of VR on the users are still inconclusive. With only a few reliable studies that investigate the effect of virtual reality on the users especially on the eyes, yet still there are a lot more things we do not know about the effects of VR. The purpose of this study was to compare the amplitude of accommodation before and after watching 3-dimesional (3D) movie utilizing VR and notebook (control group). Thirty-two participants volunteered in this study and all participants underwent amplitude of accommodation (AA) test using Royal Army Force (RAF) rule before and after watching three-dimensional (3D) movie for 30 minutes using VR and two-dimensional (2D) movie by laptop. The amplitude of accommodation between pre- and post-watching 3D movie on VR was insignificantly changed $(p=>0.05)$. The similar trend was also found after 30 minutes watching movie using laptop $(p=>0.05)$. The utilization of VR and laptop for 30 minutes did insignificantly alter the eye accommodation.
\end{abstract}

\section{Key words: Virtual reality, Accommodation, 3-dimensional, Technology, Effect}

\section{INTRODUCTION}

Virtual Reality (VR) has already existed since the end of 1960 s and it is not an entirely new concept. Previously it was given many names such as synthetic environment, cyberspace, artificial reality, and simulator technology before VR was eventually adopted. The latest concept of VR is desktop VR. Desktop VR is also known by other names such as Window on World (WoW) or non-immersive VR [1]. Virtual reality has been used in various purposes such as education, engineering, military and gaming platform.

Besides, this paper [2] found that post-traumatic stress disorder and phobias like fear of spiders and heights can be treated using virtual reality and it shows effective result. Virtual reality is also used for training and it improves performance and decision-making of the users [2]. The challenge of virtual reality world is to develop better virtual reality devices and systems to allow users to interact more naturally with the virtual reality environment. The companies that make the virtual reality devices must improve their devices for better ergonomics and less health issues when using their devices.

This paper [3] stated that the main idea of VR is to make the users feel and see through their eyes exactly like in the real situation even though it is only virtual condition. Angular movement, relative size and brightness are the visual cues that drive the perception of virtual reality. The basis of binocular vision is the fusion of different images on right and the left eyes into one 3D perception and it is very effective for near objects like in VR compared to distance objects. The equipment comprises of a goggle-like display one for each eye. The display gives different perspective images between the two eyes to create $3 \mathrm{D}$ effect to enable the user feels he is in real situation. When the

Corresponding Author: Mohd Zulfaezal Che Azemin, Kulliyyah of Allied Health Sciences, International Islamic University Malaysia, Bandar Indera Mahkota, 25200 Kuantan, Malaysia, email: zulfaezal@iium.edu.my. 
user moves his head, the image will be rapidly updated to imitate changes of head movement, thus the user will sense that the action is because of his head movement not because of the change in the image.

Accommodation is stimulated when the eye changes focus from distant to near images. It happens when the crystalline lens changes its shape because of the action of the ciliary muscle on the zonular fibres. The crystalline lens loses its ability to changes shape with increasing age and most flexible during childhood and young adult. The lens lost its nucleus rigidity thus reduces the ability to accommodate after 40 years. It is because the nucleus cannot bulge anteriorly to change its anterior curvature as in the young age. Change of the lens shape occurs at the central anterior of the lens surface based on von Helmholtz's theory.

There is lack of research about the effect of virtual reality because it is a new technology that is always developing and improving. However, there are some previous research $[4,5]$ about the effect of virtual reality on the accommodation of the eyes which are related to our study. Although previous study stated that there is no significant effect of virtual reality on the eyes, but there are some differences such as field of view, screen resolution and distance from eyes to the target and the duration of VR use compared to our current study.

This study investigated the short-term impact and effect of virtual reality on accommodation of the eyes. Some research suggested possible harmful effect of virtual reality devices especially with head mounted display [6]. It also studied the effect of virtual reality on convergence of the eyes because accommodation acts together with convergence during the process. The results of this study would benefit the healthcare providers to ensure the accommodation data taken during the eye check-up is not due to virtual reality use prior the eye examination. This study will give important information to them.

\section{METHODS AND MATERIALS}

This study has been approved by Kulliyyah of Allied Health Sciences (KAHS) Ethics Committee (KAHS 73/18). Samsung Gear Virtual Reality (VR) 2017 weighs 345 grams with $101^{\circ}$ field of view was used in this experiment. The setup was attached to Samsung Galaxy Note 8 to provide the display for the Samsung Gear VR. It has 6.3-inch screen with Active-Matrix Organic Light-Emitting Diode (AMOLED) Quad high definition (HD) and a resolution of $2960 \times 1440$ pixels with 552ppi. 13-inch Toshiba Satellite L745 notebook with 184 lux and $1366 \times 768$ pixels was used to watch 30 minutes movie for the control group. Royal Air Force (RAF) rule was employed to measure the preand post-monocular amplitude of accommodation (AA). N5 target on the RAF rule was used as the target for the participants and the measurement was taken 3 times on each eye. Occluder was used to close subject's one eye during the AA test.

Thirty-two participants among students in International Islamic University Malaysia (IIUM) Kuantan, Pahang were volunteered to become our subjects. Participants were explained about consent form and ethical consideration before being selected in the study. After participant selection, preliminary assessment was performed on the participants to screen for inclusion and exclusion criteria. The inclusion criteria were individuals with age from $18-25$ years, best corrected visual acuity; Distance at least 6/9, Near N5@40 cm, no chronic diseases, ocular trauma, ocular diseases, no accommodation insufficiency, accommodation excess, accommodation infacility, accommodation paralysis, convergence insufficiency, convergence excess, divergence insufficiency and divergence excess. The exclusion criteria were visual acuity worse than $6 / 9$ and N5 at distance and near respectively, accommodation and vergences problems.

The assessments include dry refraction, auto refractor, best-corrected visual acuity (BCVA), amplitude of accommodation, vergence tests (near point of convergence), and slit lamp bio microscopy (SLB). The BCVA was measured using Snellen Chart, the AA and near point of convergence was tested using RAF rule. After the participants pass the preliminary examination, they underwent pre-assessment of monocular amplitude of accommodation (AA) using RAF rule and the result was recorded.

Next, the virtual reality group was asked to watch 3dimensional movie with $1080 \mathrm{p}$ resolution entitled "How to Train Your Dragon 2" on Samsung Gear Virtual Reality (VR) for 30 minutes. The participants 
watch the same movie for 30 minutes on laptop for the next visit in one week. The distance between participants and laptop is 1 meter. Immediately after 30 minutes, post assessment of monocular AA was tested on the participants using RAF rule before they were discharged. In this study, besides amplitude of accommodation, we also test the short-term effect of virtual reality usage on non-invasive tear break-up time (NIKBUT), tear meniscus height, inter-blinking rate and convergence (phoria and fusional vergence).

Table 1 Comparison of amplitude of accommodation between pre- and post-watching 3D movie on VR using each eye.

\begin{tabular}{|c|c|c|c|c|c|}
\hline $\begin{array}{c}\text { No. of } \\
\text { participants }\end{array}$ & Measured eye & $\begin{array}{c}\text { Type of } \\
\text { measurement }\end{array}$ & $\begin{array}{c}\text { Time of } \\
\text { measurement }\end{array}$ & Median (IQR) & $p$-value \\
\hline \multirow{8}{*}{$\begin{array}{l}\text { Participants } \\
\text { watching movie } \\
\text { on virtual } \\
\text { reality } \\
(\mathrm{n}=32)\end{array}$} & \multirow[t]{4}{*}{ Right Eye } & \multirow[t]{2}{*}{ Break AA } & pre & $9.09(2.78)$ & \multirow[t]{2}{*}{0.243} \\
\hline & & & post & $8.71(1.67)$ & \\
\hline & & \multirow[t]{2}{*}{ Recovery AA } & pre & $8.33(2.72)$ & \multirow[t]{2}{*}{0.614} \\
\hline & & & post & $7.69(1.95)$ & \\
\hline & \multirow[t]{4}{*}{ Left Eye } & \multirow[t]{2}{*}{ Break AA } & pre & $9.09(2.50)$ & \multirow[t]{2}{*}{0.743} \\
\hline & & & post & 9.09 (1.67) & \\
\hline & & \multirow[t]{2}{*}{ Recovery AA } & pre & $8.33(2.08)$ & \multirow[t]{2}{*}{0.631} \\
\hline & & & post & $8.33(1.81)$ & \\
\hline
\end{tabular}

Table 2 Comparison of amplitude of accommodation between post-watching movie on VR and on laptop using each

\begin{tabular}{llllll}
\hline \multicolumn{1}{c}{$\begin{array}{c}\text { No. of } \\
\text { participants }\end{array}$} & Measured eye & $\begin{array}{c}\text { Type of } \\
\text { measurement }\end{array}$ & Type of devices & Median (IQR) & $p$-value \\
\hline \multirow{2}{*}{$\begin{array}{l}\text { Participants } \\
\text { watching movie } \\
\text { on VR \& laptop } \\
(\mathrm{n}=32)\end{array}$} & Right Eye & Break AA & VR & $8.71(1.67)$ & 0.640 \\
& & Recovery AA & VR & $9.09(1.67)$ & \\
& & & Laptop & $7.69(1.95)$ & 0.570 \\
\cline { 2 - 5 } & Left Eye & Break AA & VR & $8.33(1.95)$ & \\
& & & Laptop & $9.09(1.67)$ & 0.985 \\
& \multirow{2}{*}{ Recovery AA } & VR & $8.09(1.67)$ & \multirow{2}{*}{0.911} \\
& & Laptop & $8.33(1.41)$ & \\
\hline
\end{tabular}

\section{RESULTS}

Statistical analysis was conducted with IBM SPSS (Version 24.0, SPSS Inc., Chicago, Illinois, USA). The non-parametric test which was Wilcoxon signed-rank test was used for data analysis. A value of $p<0.05$ was considered significant. There were no significant differences $(p>0.05)$ in terms of amplitude of accommodation of the thirty-two participants between pre- and post-watching 3D movie on virtual reality for 30 minutes on both eyes (Table 1). There were also no significant differences $(p>0.05)$ of amplitude of accommodation between post-watching movie for 30 minutes on virtual reality and notebook (Table 2).

\section{DISCUSSION}

Our results are consistent with the previous study which showed that there was no significant effect of virtual reality headset on the accommodation [4]. The study used negative relative accommodation (NRA) and positive relative accommodation to test for accommodation of the eye. The study also compared the effect of playing games on head-mounted display (HMD) virtual reality and on cathode ray tube (CRT) display, equipped with i-glasses head-mounted display made by Virtual I/O (Seattle, WA) as the main instrument of virtual reality. The i-glasses has display of $789 \times 230$ pixels and field of view of $25 \times 20^{\circ}$. The 
interpupillary distance of the device is fixed at $61 \mathrm{~mm}$. The research work used computer game named Ascent (Gravity, San Francisco, CA) as a stimulus on the display on 37 subjects and the time exposed on HMD and CRT was 30 minutes. The result showed no small changes occurred on the accommodation when using the device. Another study also measured the amplitude of accommodation using RAF rule after playing game for 40 minutes on virtual reality headset and the result was also not significant [5]. It can be concluded that even though using different type of virtual reality headset for 30 minutes, the result on the accommodation has no significant effect.

Another drawback of this study was we were not able to ensure the participants to really watch the movie on the virtual reality as the current setting did not allow for monitoring the eye fixation. They might close their eyes while watching the movie which resulted in no change in amplitude of accommodation because the eyes were not focus on anything. According to [7], accommodation is the change in optical dioptric power of the eyes that allows the point of focus of the eyes changed from distance to near targets. If the participants did not open the eyes and focus on the near screen in virtual reality headset, the accommodation cannot take place. So, to overcome this drawback, we observe the behavior of our participants and talk to them when we noticed no response from them through their behavior to ensure they were awake.

Our participants aged from eighteen to twenty-five years which were categorized as young adults according to [8]. We hope that in the future there will be a study to investigate the effect of VR on children because their interpupillary distance is smaller and their amplitude of accommodation is high, so they need more concern than adult [5]. No statistically significant differences were found in the accommodation responses when reading on smartphones and tablets for 10 minutes according to [9]. The study used iPhone $4 \mathrm{~S}$ and iPad Mini as the display to display the text for the subjects to read for 10 minutes to test for the accommodation responses. This study was related with our study in term of smartphone usage as a display. The differences were the duration of the test and the type of resolution of the smartphone.
Our test was 30 minutes of usage while their study was only tested for 10 minutes of using the smartphone. The resolution of iPhone $4 \mathrm{~S}$ and Samsung Galaxy Note 8 also different whereby iPhone $4 \mathrm{~S}$ has only 960 x 640 pixels with 326 ppi and the Samsung Galaxy Note 8 has $2960 \times 1440$ pixels with 552 ppi. The distance between patient's eye and the focusing point is also different; in our study we used $10 \mathrm{~mm}$ distance, while [9] used distance of 0.25 meter from the subjects' eyes to the screen of the smartphone. Therefore, the duration of using VR for 30 minutes with display's resolution of $552 \mathrm{ppi}$ and $10 \mathrm{~mm}$ distance from display to the eyes did not give any significant change to accommodation of the eyes.

\section{CONCLUSION}

Our findings support the previous study that there is no short-term effect on the accommodation of the eyes when using virtual reality headset for a short period of time. However, further study must be conducted to test the effect of virtual reality headset for longer period and younger population. Our study also proved that there is no significant difference on the accommodation system between watching movie on virtual reality headset and laptop.

\section{ACKNOWLEDGEMENT}

We would like to thank and appreciate to the coresearchers, Mohd Syarifuddin Bin Sidik Ahmad, Anas Bin Ibrahim and Hafizah binti Zaini that were very helpful in data collection process in this study. We also want to thank to all participants for involving in this study. Their contributions are really appreciated and greatly acknowledged. This work is supported by the International Islamic University Malaysia (IIUM), under the Research Initiative Grant (P-RIGS18-0350035).

\section{REFERENCES}

[1] Onyesolu, M.O. and Eze, F.U. 2009. Understanding Virtual Reality Technology. Advances and Applications, 53-70.

[2] Mandal, S. 2013. Brief Introduction of Virtual Reality and its Challenges. International Journal of Scientific and Engineering Research, 4, 4, 304-309.

[3] Smith, S. and Lee, S. 2004. A pilot study for integrating virtual reality into an introductory design 
and graphics course. Journal of Industrial Technology, 20, 4, 2-7.

[4] Peli, E. 1998. The visual effects of head-mounted display (HMD) are not distinguishable from those of desk-top computer display. Vision Research, 38, 2053-2066.

[5] Turnbull, P.R.K. and Phillips, J.R. 2017. Ocular effects of virtual reality headset wear in young adults. Scientific Reports, 7, 1, 16172, https://doi.org/10.1038/s41598-017-16320-6.

[6] Cobb, S.V.G., Nichols, S., Ramsey, A. and Wilson, J.R. 1999. Virtual reality-induced symptoms and effects (VRISE). Presence, 8, 2, 169-186, https://doi.org/10.1086/250095.

[7] Glasser, A. 2011. Accommodation. Adler's physiology of the eye, Oxford, Saunders, 40-70.

[8] Bleyer, W.A., Albritton, K. 2003. Definition of Older Adolescent and Young Adult. Holland-Frei Cancer Medicine, 6th edition, Hamilton.

[9] Moulakaki, A.I., Recchioni, A., Aguila-Carrasco, A.J., Del, Esteve-Taboada, J.J. and Montes Miro, R. 2017. Assessing the accommodation response after near visual tasks using different handheld electronic devices. Arq Bras Oftalmol, 80, 1, 9-13, https://doi.org/S0004-27492008000500023. 